4. Diagnosis was established from the progressive muscular weakness, lack of mental development and blindness with pathognomonic changes in the fundus.

In conclusion, I have to thank Dr. William Heng for assisting me with the notes of this case, Dr. Chew Poh Kuo for the original diagram of the appearance of the left fundus, and the Director of Medical Services, Singapore Union, for permission to publish this case.

\title{
REFERENCES
}

Baker, A. B. and Platou, E. (1938).-Arch. Path., Vol. XXV, p. 75.

Bielschowsky, M. (1920)-Jl.f. Psychol. u. Neurol., Vol. XXVI, p. 123. (1928). - Ibidem, Vol. XXXVI, p. 131.

CARTER (1894).-Arch. of Ophthal., New York, Vol. XXIII, p. 126.

HAMBURGER, R. (1927). -Jahrb. f. Kinderh. Berlin. Vol. CXVI, p. 41.

Kamel Yacoub (1938).-Jl. of Egypt Med. Assoc., Vol. XXI, p. 377.

KINGDON (1894). -Trans. Ophthal. Soc. U.K., p 14.

KuFs, H. (1933).-Zeitschr.f.d. ges. Neurol. u Psychist., Vol. CLV, p. 565.

MOTT (1907).-Arch. of Neurol., Vol. III, p. 218.

PICK, L. (1933).Amer. Jl. Med. Sc., Vol. CLXXXV, p. 601.

Poynton, Parsons and Holmes, Gordon (1906).-Brain, Vol. XXIX, p. 180.

SaChs, Bernard (1887).- Jl. of Nerve and Mental Dis., New York, Vol. XIV, p. 541.

(1896).-Ibidern., Vol. XXXI, p. 475

SchAFFER, K. (1935)-(1935).-Deutsche Zeitschr. f. Nervenh., Vol. CXXXV, p. 11 .

Slome. D. (1933).-Jl. Genetics, London, Vol. XXVII, p. 363.

SPIElmeyer, W. (1929).-Jl.f. Psychol. u. Neurol., Vol. XXXVIII, p. 120.

WAREN TAY (1850-1851).-Trans. Ophthal. Soc. U.K. Lond., Vol. I, p. 55.

\section{TECHNICAL IMPROVEMENTS IN THE DIATHERMY OPERATION FOR DETACHMENT OF THE RETINA}

\author{
BY
}

\author{
Prof. A. Kettesy \\ DEBRECEN, HUNGARY
}

THE diathermy operation for retinal detachment, in spite of its great development, still has such technical difficulties, which may be eliminated by improvement of the instruments used in the principal phase of the operation, the coagulative closing of the hole by the pointed perforating electrode.

There have been two main forms of perforating electrodes in use up to date : the needle, as described and used by Weve, Vogt; Szily-Machemer and others, and the nail of Safar and Arruga.

The drawback of the needle is that it has to be pulled out after every puncture. There arise leaking channels through the sclerotic and choroid from the beginning, with more or less continuous loss of inter-retinal fluid. Their number increases during the operation necessarily, hence the eye softens and the scleral surface 
cannot be kept dry. Both circumstances make the further punctures more and more difficult, till at last it is sometimes impossible to continue with diathermic perforations, and one is obliged to change to other means, e.g., to the cautery-loop.

Attempts have been made to avoid these inconveniences by shortening the working length of the needle and by refining its point. The depth of the puncture should not exceed $1.0-1.5 \mathrm{~mm}$., so as to reach the choroid, but not to pierce it. Yet, this form had its own disadvantages, too. Too small an area of coagulation behind the retina could not always be seen by the ophthalmoscope, hence the control became doubtful. Moreover the coagulative effect would not suffice sometimes to arouse the necessary adhesive inflammation.

The nails, inserted, remain in place during the main phase of the operation. The Safar nail is still the best, yet set into the sclerotic its head protrudes $2 \mathrm{~mm}$. above the scleral surface. Whenever the eye is turned back into the primary positionnecessary for ophthalmoscopic control-the head of the nail is caught in Tenon's capsule. In consequence of this the head is either laid flat down on the sclerotic or lifted out. In the first case the point of the nail is vacillating inside, a great danger to the retina and the vitreous. Laid flat down on the choroid its discovery with the ophthalmoscope is rendered difficult. On the other hand, if taken out or loosened, it brings about the inconveniences of the filtrating channel. Besides it has eventually to be sought in the tissues. (Therefore nails should be as a rule always counted.)

There have been still more drawbacks in Safar's set. His insulated forceps did not seize the nail firm enough. During the insertion it readily tilts over. The forceps is too clumsy, its faces are too large, and sometimes it is difficult to get deep enough with it into a narrow slit.

All disadvantages can be eliminated by giving a better shape to the nail and by constructing suitable forceps for it.

This new nail is made of highly polished stainless steel. It has a round flat head, not thicker than $0.3 \mathrm{~mm}$. and with a diameter of $15 \mathrm{~mm}$. The length varies from 2 to $6 \mathrm{~mm}$. It begins cylindrically and passes conically into a sharp point (Fig. 1).

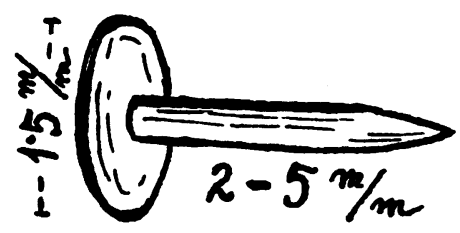

FIG. 1.

The new diathermic nail magnified. 
The new insulated forceps has angular ends. On the inner side of each end a small groove runs all along the three margins (Fig. 2). The parallel grooves work together and are designed to catch the nail.

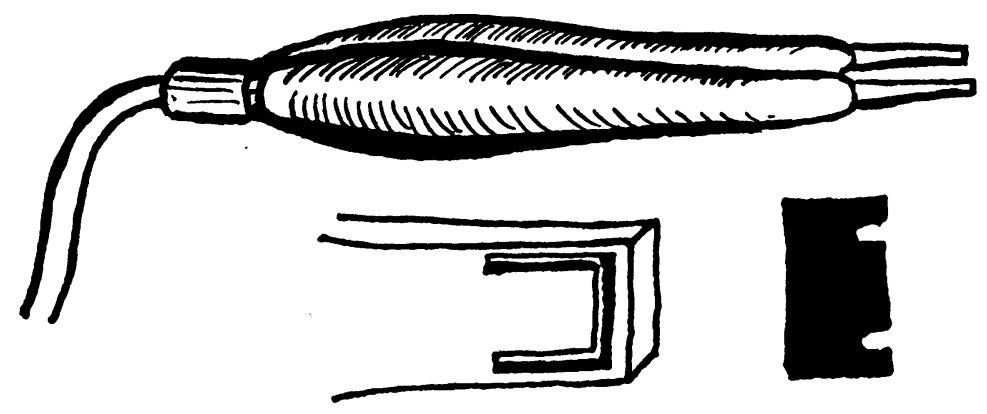

FIG. 2.

The isolation-forceps in full-shape, the grooved inner surface of the end and its cross-section.

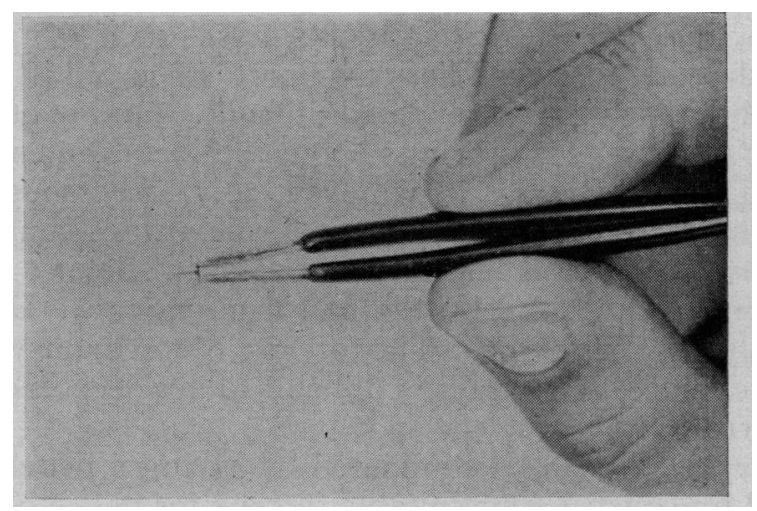

FIG. 3.

The nail seized with the isolation forceps perpendicularly.

The nail is easily seized by this forceps and directed as well in the axis of the forceps as perpendicularly to it (Figs. 3 and 4). The head of the grasped nail is held immobile in the forceps.

In order to keep the nails arranged at hand, and to protect them from being lost, we preserve them in cork-plates, taking them from there and putting them back there (Fig. 5).

Working with this equipment there are no disturbing moments in the course of the operation. As we use the nails not only for the closing of the hole, but at the same time for localisation, some 


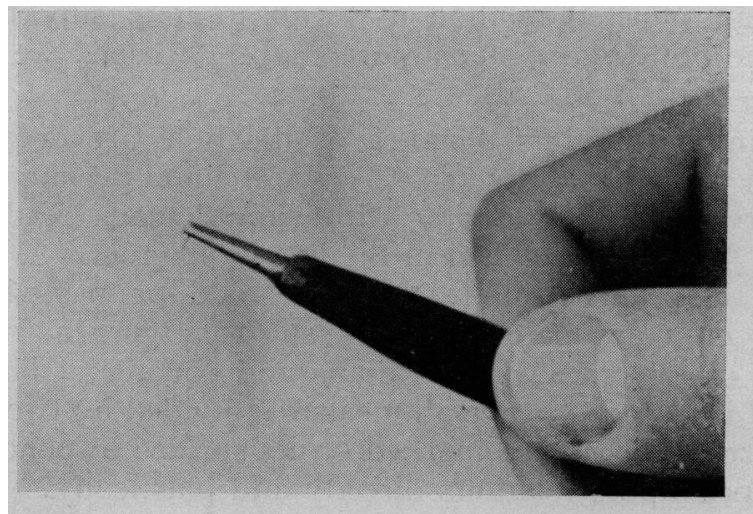

FIG. 4.

The nail seized vertically.

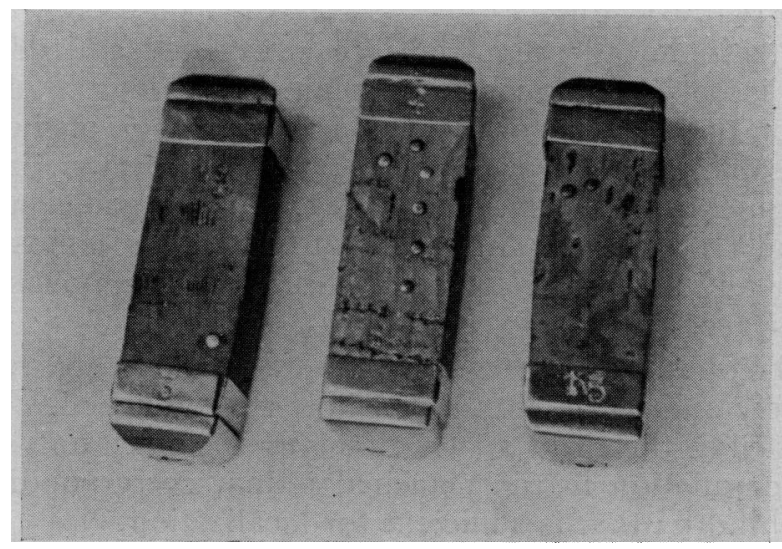

FIG. 5.

The nails arranged on cork plates.

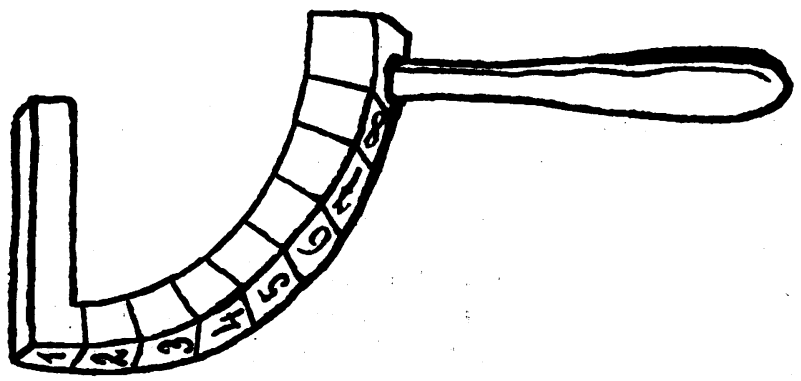

FIG. 6.

Small perimeter. 
separate complicated method of localisation is superfluous, thus making the preparatory steps more simple. Briefly we proceed as follows :-

Meridian and limbus distance of the hole are determined by estimation and the perimeter. A small hand-perimeter (Fig. 6) allows direct ophthalmoscopy with simultaneous reading of the degrees. A plan is sketched in the known manner. We found an agreeable help an eyeball made of wood or paste-board. All necessary data are painted on its surface : cornea, ora serrata, insertions of the muscles, meridians and equator. The diameter of the ball is $44 \mathrm{~mm}$., hence all measures divided by two are giving natural size. The hole is marked on its surface in pencil, thus we see the topographic relations directly and plastically.

We do not instil cocaine, thus diminishing the danger of the corneal surface becoming hazy. A drop of pantocaine suffices to be able to make the local anaesthesia with subconjunctival injections of novocaine.

The corresponding scleral surface is exposed and dried. The first nail is set in following the plan. The length of the nail depends on the diastasis of the retina in the region of the hole, yet it is advisable to choose a long one, say 5 or $6 \mathrm{~mm}$., in order to find it quickly by ophthalmoscopy. With sufficient current $(20-30 \mathrm{~mA}$.) the nail plunges into the eye almost without resistance and the head adheres closely and immovably to the scleral surface.

With the ophthalmoscope the point of the nail is generally found immediately and its relation to the hole is established. With luck the nail strikes the right spot. Sometimes we see only the white spot of coagulation in the detached retina, corresponding to the needle behind it; that is sufficient for localization.

If the first nail is in a wrong position we settle the place of the next nail by estimation, e.g., $3 \mathrm{~mm}$. backwards meridianally and $2 \mathrm{~mm}$. temporal or nasal longitudinally. The nail put in, new ophthalmoscopic control follows: It is superfluous to say that all nails set in remain preliminarily in their place. If necessary, we put in a third and fourth nail, till we did hit the hole or its margin somewhere, thus being able to get an easy start to put in all the other nails around the hole. These nails are shorter, $2-3$ $\mathrm{mm}$.

An example of an operation is shown in Fig. 7.

There is a typical hole of horseshoe form, meridian 2.30 o'clock, $13 \mathrm{~mm}$. from the limbus. The first needle of $5 \mathrm{~mm}$. hits the middla of the hole. With the following needles of $3 \mathrm{~mm}$. length we mark the main points of the planned lines of coagulation, checking their 


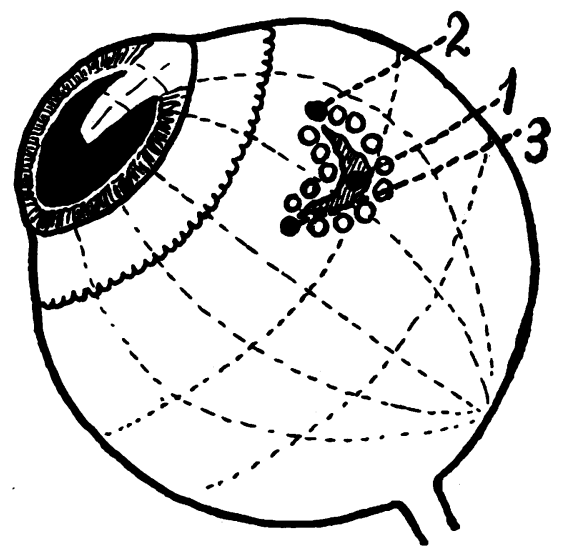

FIG. 7.

Plan and course of a detachment operation.

right position by ophthalmoscopic examination we fill up the lines with nails of $2 \mathrm{~mm}$.

Having put in the last nail, an ophthalmoscopic control may follow, yet is not necessary.

The nails are quickly removed one after the other with the grooved forceps, and the operation field closed. (The nails are counted.)

There arises no harm from the nails in the wrong position or having perforated the retina. All such points give rise to small local inflammations, contributing to the adhesion of the re-attached retina.

It did not seem to be necessary to insulate the head of the nail or the upper part of its shaft, though it could be done. Bare nails compared with insulated needles did not show any difference in working.

For more than 3 years I have been using this set. Having gone through the whole evolution of the detachment-operation in the practice, I find it is superior to all other sets from the technical point of view. We make ophthalmoscopic examinations of the patient lying on the operating table and we start the operation only when we are certain of finding every detail of the fundus quickly and surely in this unaccustomed position. This and the technique together have contributed much to shorten the operation and to keep the cornea clear. The operation has become more exact, and this manifests itself in the increased percentage of the successful cases. 